\title{
BIOGRAFÍAS MÉDICAS. UNA REFLEXIÓN \\ DESDE LA AMBIGÜEDAD
}

\author{
Luis Montiel \\ Unidad de Historia de la Medicina. Facultad de Medicina. UCM.
}

\section{RESUMEN}

Se propone una ampliación del concepto «biografías médicas» al conocimiento de aspectos de la vida del paciente, en la perspectiva de una historia de la medicina centrada en él. En cuanto a la noción más clásica, se resalta su papel en la creación de una «atmósfera» susceptible de afinar la comprensión de los temas estudiados por el historiador de la medicina.

PALABRAS CLAVE: Historia de la medicina centrada en el paciente, biografía médica, historia clínica, medicina y literatura.

\section{SUMMARY}

The main aim of the paper is a proposal to enlarge the concept of «Medical Biographies» in other aspects of the patient's life, in the context of a Medical History centred on the patient. With regards to the classical notion, it is important to underline the role played by scientific biographies creation of a special atmosphere that allows a more precise understanding of subjects studied by historians of medicine.

KEY WORDS: History of Medicine centred on patient, medical biography, medical records, medicine and literature.

\section{BIOGRAFÍAS DE MÉDICOS Y BIOGRAFÍAS MÉDICAS.}

Antes de comenzar a cumplir con mi cometido deseo agradecer muy sinceramente a quienes me han encomendado esta tarea su confianza e interés. En su intervención de bienvenida al simposio, Consuelo Miqueo, en nombre de la organización, tuvo unas cordiales palabras hacia aquellos enfoques del tema que, pudiendo ser dignos de atención, no habían tenido cabida en el mismo por la inevitable limitación del tiempo disponible. Después, Rosa Ballester en su condición de presidenta de la Sociedad Española de Historia de la Medicina, y José Luis Peset como director de Asclepio, me propusieron 
añadir algo a la mucho y bueno que allí se dijo. Acepté, como puede verse, de muy buen grado, y hago ahora extensiva mi gratitud a todos los compañeros dispuestos a recibir amistosamente esta páginas mías, pues amistosamente las escribo, lo que no excluye el propósito de aportar argumentos susceptibles de tenerse en cuenta a la hora de plantearse el trabajo en lo que, de manera amplia y, por tanto, nada excluyente, se ha llamado en el título del simposio «biografías médicas».

Las tres personas cuyos nombres acabo de mencionar se refirieron a la literatura, y entiendo que su invitación apunta, al menos parcialmente, en este sentido. Sin embargo, declaro desde este momento no sentirme capaz de ceñirme de manera exclusiva a tal enfoque, aunque, por razones obvias - se trata de uno de mis campos de trabajo predilectos- espero no defraudar sus expectativas. Simplemente me veré obligado a dar al término «literatura» una extensión algo mayor de lo habitual. Por otra parte, la reflexión que su propuesta me ha suscitado me obligará a referirme a mi propia experiencia algo más de lo que quizá admitiría el buen gusto. No lo haré, no lo hago, con afán magistral. Simplemente quiero compartir algo que para mí ha tenido sentido con interlocutores que, en muchos casos, para mi fortuna, lo son desde hace tiempo, y siempre cordiales hasta en la discrepancia.

Me pregunto, en primer lugar, qué puede entenderse por «biografías médicas», pareja de términos bastante ambigua a mi parecer. ¿Significa, acaso, «biografías de médicos»? ¿Por qué, entonces, no enunciarlo de este modo, sin duda más preciso? Dio la impresión de que esa era la intención de las organizadoras, y de hecho fue la línea que se siguió en el simposio. Pero quizá el lenguaje, o mejor su fuente inconsciente, les tendió una trampa, pues en su fuero interno aspiraban a más. ¿Será tal vez ésa la razón por la que estoy ahora escribiendo?

Creo que desde el momento en que todos los interesados tuvimos noticia del tema se puso en marcha una ola de sospecha y de expectativa. Sospecha, porque ante nuestra memoria se presentaba sobre todo la imagen de esas obras, escritas o filmadas, en las que se nos presenta idealizada la figura del héroe científico, del santo laico - a veces incluso confesional-, del personaje modélico que sólo desconfianza puede suscitar en quienes nos dedicamos con seriedad a la historia de la teoría y de la práctica de la medicina. Expectativa, porque el mero hecho de proponerlo como tema de estudio implicaba la convicción de que se podía hacer de otro modo, al servicio de ese objetivo común que desde múltiples perspectivas venimos persiguiendo en todas nuestras reuniones. Como todos, yo también comencé a reflexionar sobre el asunto, y desde luego evoqué mis experiencias con la literatura, espacio privile- 
giado de la biografía propiamente dicha, y de esa biografía imaginada que es la novela; pero me sorprendí reconociendo que al preguntarme de cuándo data mi interés por las «biografías médicas», debí reconocer que su origen no se encuentra en ninguno de mis trabajos sobre «medicina y literatura», sino en un texto por el que siento un cariño especial: el primero que dediqué a una historia clínica de Dietrich Georg Kieser ${ }^{1}$. En él apenas contaba nada de la vida del médico, pero recogía con emoción sus propias palabras al comienzo del relato patográfico: "Karoline M., de K., de 18 años de edad, de figura delgada, color de tez pálido, temperamento vivo, constitución sensible — rasgos éstos no manifiestos en su aspecto externo, sino que fueron mostrándose en el curso de la historia - habia gozado de buena salud hasta el año 1829. Poco antes habia provocado la interrupción de su flujo menstrual para poder participar en un baile, bebiendo vinagre... $\rangle^{2}$. Aquel texto era más que una historia clínica, más que el relato de un caso; era, en el sentido más propio del término, narrativa, literatura. Como lo era, y aún más, el relato de otro caso que figuraba en la misma obra, del que me he ocupado más recientemente: el de un diácono que sufre horriblemente al sentirse perseguido por la policía a través de un maligno instrumento — una «cadena galvánica»— que controla sus pensamientos ${ }^{3}$. No se me escapaba que esta peculiaridad podía deberse a la época; no en vano el romanticismo concedió a la novela un estatuto cuya dignidad no se habían atrevido a atribuirle etapas precedentes de nuestra cultura $^{4}$. En todo caso, lo cierto es que la biografía, la aventura lamentable que en ambos casos se refería, no era la del médico, sino la del paciente. Es decir: mi primer encuentro con la «biografía médica» no se produjo en absoluto a través de la biografía de un médico; al contrario, era el médico quien hacía de la biografía del enfermo una parte de su quehacer ${ }^{5}$. Cierto es que, en el se-

1 Montiel, L. (1990), «Una historia clínica romántica. Contribución al conocimiento de la Patología de la Naturphilosophie», Medicina e historia, 31, pp. 1-16.

2 KIESER, D.G. (1834), Klinische Beiträge, Leipzig, p. 191.

3 Montiel, L. (2001), «Historia y enfermedad mental en dos historias clínicas de Dietrich Georg Kieser (1779-1862)», Frenia, 1- 2, 67-85.

4 «Las novelas son los diálogos socráticos de nuestro tiempo. En esta forma liberal ha buscado refugio la sabiduría de la vida huyendo de la sabiduría de la escuela». SCHLEGEL, F. (1994), Poesía y filosofía. Ed. de D. Sánchez Meca y A. Rábade Obrado. Madrid, Alianza Editorial, p. 49. Cfr. D’Angelo, P. (1999), La estética del romanticismo, Madrid, Visor, pp.181-200. En cuanto a la biografía propiamente dicha, cfr. GUSDORF, G. (1993), Le romantisme, I, Paris, Payot, pp. 382-383.

5 El mismo Kieser escribe al respecto: «Toda historia clínica, como monografía de una enfermedad individual, debe contener una patología y una terapéutica completas de esa en- 
gundo de los casos que acabo de mencionar, el del diácono, me ocupé algo más de la figura del médico - del narrador-, pues, saldada la deuda con el protagonismo de los pacientes en ambos trabajos, sentí la necesidad de conocer mejor al clínico que escribía sus historias dando tanto lugar a las manifestaciones del enfermo.

Por otra parte, en el ínterin me había encontrado con la biografía de otro médico romántico, tan Naturphilosoph como pueda desearse, que convenía conocer: la de Lorenz Oken ${ }^{6}$; y ello no tanto para la mejor comprensión de su obra cuanto para salir al paso de las tópicas descalificaciones de que han sido objeto los autores de este período, todos ellos sospechosos por igual de idealismo especulativo y de desvinculación solipsista de la realidad social e histórica. La peripecia política de este autor, sin ser, desde luego, la norma, sirve al menos para mostrar que no siempre es mejor la historia de la medicina que se hace sin saber cómo vivieron algunos de sus titulares.

\section{ENTRE CIENCIA Y POESÍA: BIOGRAFÍAS LITERARIAS.}

Con todo, faltaría a la verdad si no matizara el aserto formulado al comienzo del apartado precedente. Tal vez sea cierto en alguna medida que mi interés por la biografía tenga un origen literario. Pero, en ese caso, debería remontarme bastante más corriente arriba de mi vida, y tal vez atribuir a tales orígenes mi definitiva elección profesional, la que ha hecho de mí un historiador de la medicina. Antes incluso de entrar en la universidad leí dos apasionantes biografías literarias: la de Fouché7 escrita por Stefan Zweig, y la de Napoleón, por Emil Ludwig8. Como puede verse, ninguna tiene por protagonista a un médico. Sólo más tarde supe que el primero de estos autores se había ocupado también de Mesmer, de Freud y de Servet ${ }^{9}$, y que junto a los primeros había colocado a un personaje que, sin ser médico, había tenido mucho que ver con el mundo de la curación — por el espíritu—: Mary Baker

fermedad, e indicar la diferencia individual del ser humano que la sufre, en virtud de la cual esa enfermedad ha llegado a ser enfermedad individual, asi como los momentos particulares que determinan su curación». KIESER, D.G. (1834), 632.

6 Montiel, L. (1999), «Una Summa de la filosofía de la naturaleza del romanticismo alemán: el Lehrbuch der Naturphilosophie de Lorenz Oken», Asclepio, LI-2, 205-220.

7 ZWEIG, S. (1956), Fouché. El genio tenebroso, Barcelona, Editorial Juventud.

8 Ludwig, E. (1956), Napoleón. Barcelona, Editorial Juventud.

9 ZweIG, S. (2001), Castellio contra Calvino. Conciencia contra violencia, Barcelona, El Acantilado. 
Eddy $^{10}$. Es sabido que, sin que puedan considerarse obras de referencia, las de Zweig son biografías bien documentadas, que no faltan a la verdad y que, en algún caso son resultado de un trabajo de muchos años: la última de las suyas, la de Balzac, hasta ocho. Biografías que sin duda pretenden cautivar al lector - se escriben para ser vendidas y leídas - , pero trabajadas con respeto y seriedad, y que resultan atrayentes en primer lugar por lo sucedido al personaje o lo realizado por él; sólo sobre ese material puede aportar algo complementario la técnica del escritor. Por más que sea cierto que una golondrina no hace verano, si verdaderamente esas biografías tuvieron que ver, en la distancia y sumadas a otros factores, con la decisión de un clínico de pasarse con armas y bagajes a la historia de la medicina, ya puede decirse que han hecho algo en favor de ésta. Tampoco puedo, ni quiero, olvidar que - como sin duda conoce la mayoría de mis compañeros - mi llegada a la historia de la medicina se produjo en el mismo tren que conducía a Hans Castorp a La montaña mágica. Mi tesina de licenciatura (1978), dirigida por los inolvidables Agustín Albarracín y Pedro Laín llevaba por título Antropología médica en «La montaña mágica» de Thomas Mann.

Y sin salir del mundo de la literatura: ¿qué pensar de un estudio literario que prescinda del conocimiento de las circunstancias de la vida de su autor? Doy fe de que es posible, pero insatisfactorio. Yo mismo escribí un libro analizando tres de las novelas fundamentales de Gustav Meyrink ${ }^{11}$ sin mencionar siquiera su fecha de nacimiento, y creo que puede leerse y que cumple el objetivo que entonces me propuse. Y, sin embargo, siempre he sentido que faltaba algo, que estaba en deuda con eventuales lectores, de modo que finalmente tuve que contar la biografía de Meyrink ${ }^{12}$ que, por cierto, no es obra mía ${ }^{13}$. Con esta anéc-

10 Las biografías de Mary Baker-Eddy, Sigmund Freud y Franz Anton Mesmer, agrupadas bajo el título La curación por el espíritu, aparecieron en castellano por primera vez, respectivamente, en 1929, 1949 y 1951 en la editorial Apolo, de Barcelona. Actualmente no hay edición alguna disponible en castellano.

11 Montiel, L. (1998), La novela del inconsciente. El proceso de individuación en la narrativa de Gustav Meyrink, Barcelona, MRA.

12 Montiel, L. (2003), «Una consideración intempestiva sobre el origen de la guerra: Das Grillenspiel de Gustav Meyrink», Frenia, III-2, 33-53. MonTIEL, L. (2004), «En el espejo oscuro de la magia, en el tornasolado del espíritu. John Dee y Gustav Meyrink», En: CONDE, A.; Leyra, A.M.; del Prado, J; Scrimieri, R. (Eds.), La Europa de la escritura, Madrid, Ediciones de La Discreta, pp. 87-120.

13 La mejor biografía de Meyrink, en cierto sentido definitiva — pues existen algunas lagunas que parece muy difícil colmar por falta de datos- es la de SMIT, F. (1988), Gustav Meyrink. Auf der Suche nach dem Übersinnlichen, München, Langen Müller. 
dota creo que sucede algo parecido a lo ocurrido a la «historia del arte sin nombres» propuesta por Wölfflin en 1915: es perfectamente realizable, e incluso válida. Pero a la postre todos, sin excepción, acaban escribiendo nombres en la historia del arte, de las artes; afortunadamente, hay que decirlo.

No parece que la historia de la medicina deba ser una excepción. De lo que se trata es de no incurrir en uno de esos temores informulados a que me refería: que esos nombres puedan llegar a eliminar la presencia de lo (y los) innominados; que los árboles - en un sentido bastante diferente al orteguiano- no dejen ver el bosque. Huir del estereotipo romántico del genio, probablemente el único al que han seguido rindiendo tributo, machaconamente, muchos de los detractores del romanticismo. Los médicos alemanes que he citado no son, ni siquiera a nivel local, grandes figuras de la medicina, y sin embargo sus biografías permiten entender mejor algunos momentos de la historia de aquella que hasta hace poco parecían carecer de interés.

\section{¿BIOGRAFÍAS DE MÉDICOS O BIOGRAFÍAS DE CIENTÍFICOS?}

En este punto me veo obligado a volver - también machaconamente, lo reconozco con sonrojo- sobre una de mis obsesiones. Las biografías «geniales» en medicina, las hagiografías de médicos, son obra de una historia de la medicina entendida unilateralmente como historia de la ciencia. Sus protagonistas son «grandes descubridores», «revolucionarios», «innovadores». ¿Quién de nosotros, profesionales de la materia, ha leído o conoce de oídas una sola biografía ensalzadora de un médico cuyo mérito haya sido atender durante años a cincuenta pacientes en un barrio pobre? Se me dirá - me lo dirá el que sea algo «mayor», y con ciertas lecturas- que existen biografías de Albert Schweitzer; y de la Madre Teresa de Calcuta, respondo yo, pero su procedencia y pretensiones nos permiten tomarlas por «biografías médicas» solamente de manera tangencial. En cambio, quienes entre nosotros se dedican a la historia social de la medicina o a lo que propongo llamar — no sé si el término tiene ya copyright - historia centrada en el paciente no tienen más remedio que realizar incursiones, a veces profundas, en la biografía de ciertos personajes; incursiones que comúnmente están muy lejos de cualquier idealización, sobre todo cuanto más se apartan de la superficie. En cambio, la delineación prosopográfica de una figura de la medicina - un creador de nuevas disciplinas, un descubridor de nuevos hechos científicos, un afamado publicista en las revistas de mayor prestigio, un miembro de varias academias...se presta a maravilla, desde su presunta objetividad, a la santificación del 
personaje que, en ocasiones, no resiste la confrontación con la imagen del mismo que podría suministrar una biografía detallada. Aunque, a veces, también las biografías detalladas pueden idealizar a su protagonista.

En este punto me viene a la memoria un dato que, de nuevo, tiene que ver con mi dedicación a la literatura. Cuando trabajaba en mi tesis doctoral, a finales de los años 70 y comienzos de los 80 , los estudios biográficos dedicados a Thomas Mann pasaban como de puntillas sobre sus tendencias homosexuales, y en general sobre los aspectos más negativos de su personalidad, lo cual dificultaba a menudo el trabajo sobre su obra. Fue preciso esperar hasta 1982 para que algunos de ellos se mostraran sin tapujos en la obra de ReichRanicki titulada Thomas Mann y los suyos ${ }^{14}$, y en lo que atañe a la homosexualidad, a la publicación en 1991 del estudio, a menudo vitriólico, no sin razón, de Marianne Krull sobre La familia Mann ${ }^{15}$. Más recientemente el tema de la homosexualidad ha podido, por fin, convertirse casi en Leitmotiv de una biografía que lo aborda de manera mucho más positiva ${ }^{16}$.

Vuelvo, después de este excurso, a mi argumentación precedente: la práctica asistencial no es sólo - y a menudo no es, sin más ni más- el ejercicio de una ciencia. Rothschuh lo formuló de manera explícita hace casi treinta años: «El hecho de que [teorías] médicas no validadas e inexactas puedan aplicarse reposa en el hecho de que la mayoría de enfermedades se curan solas $\rangle^{17}$. En el encuentro clínico se pone en juego lo personal, que, como es lógico, no debe entenderse en el sentido de lo supremamente individual - suponiendo que algo así exista - , sino en el de lo condicionado por todo el enorme bagaje de una cultura. Por más que uno se esfuerce por negarlo, en ese campo de operaciones uno se encuentra - aprovecharé el magnífico don que nos legaron los griegos - con bíos, y no, como sin duda nos gustaría a todos en más de una ocasión, con zoé; y esto del lado del paciente, sin duda, pero también del lado del médico, pues su presunta objetividad ni siquiera queda limitada al territorio de zoé, dado que la idea que se tenga de lo biológico es, también, un hecho histórico. Aunque apenas acabo de escribir esto se me viene a las mientes el texto de un póster científico que acabo de ver en mi

14 Reich-Ranicki, M. (1982), Thomas Mann und die Seinen, Tübingen, Francke. Trad. esp.: Thomas Mann y los suyos, Barcelona, Tusquets, 1989.

15 Krull, M.(1991), Im Netz der Zauberer, Zürich, Arche. Trad. esp.: La familia May, Barcelona, Edhasa, 1992.

16 KurzKe, H. (1999), Thomas Mann. Das Leben als Kunstwerk, München, Beck. Trad. esp.: Thomas Mann. La vida como obra de arte, Barcelona, Galaxia Gutenberg, 2003.

17 Rothschun, K. (1978), Konzepte der Medizin im Vergangenheit und Gegenwart, Stuttgart, Hippokrates Verlag, p. 7. 
Facultad. Uno de sus apartados se titula «Propósito», y el texto del mismo comienza diciendo: «La propósito es una mujer de 69 años...». Y eso me obliga a recordar tantas y tantas historias clínicas no sólo actuales, en las que deliberadamente se «zoifica» al paciente. ¿Quién sabe? Tal vez la historia de la medicina del siglo veintiuno sea verdaderamente una historia sin nombres, o con los solos nombres de aislados colosos del saber médico, más o menos coincidentes con la nómina de los Premios Nobel.

Pero no siempre ha sido así. Hoy la medicina dice construirse desde la fisiología, y hay quien sostiene - o mejor, sostuvo hasta su muerte, hace pocos años- que tal cosa es un error ${ }^{18}$. Pero hasta fechas recientes se construyó desde la clínica, y ese origen, incluso en los momentos más áridos, la iluminaba con tonos que despertaban el deseo, la necesidad de saber más acerca de sus personajes ${ }^{19}$. Incluso apartándonos del momento actual, si nos retrotraemos al Renacimiento, podemos aceptar, siendo conscientes de que sin duda perdemos algo, que la biografía de Vesalio aporta poco a la comprensión y a la valoración de su obra anatómica, pero sin un mínimo perfil biográfico no podríamos entender nada de la medicina de Paracelso, cosa que por cierto, ha ocurrido hasta fechas recientes, quedando al gusto de cada cual la elección entre el desprecio y la adoración fanática.

Otro tanto ocurre con los médicos que han desarrollado reformas institucionales, o desempeñado tareas políticas y/o sociales. ¿Qué puede haber más insatisfactorio que conocer tan sólo el nombre y las fechas liminares de la vida del fundador de un hospital notable, o del iniciador de una nueva manera de enseñar la medicina, o del organizador de una campaña sanitaria? Si no sabemos «qué pasó», y cómo ocurrió lo que ocurrió, y por qué fue así y no de otra manera, es como si nos faltara lo esencial. También aquí el mayor número de datos biográficos se revela como altamente valioso. Recientemente he encontrado un caso semejante, el de David Ferdinand Koreff (1783-1851). Su nombre no figura en las historias generales de la medicina, y cuando aparece en estudios monográficos se menciona su dedicación a la práctica del magnetismo animal y su decisivo papel en la implantación de la docencia de esta

18 CAnguilhem, G., especialmente en Le normal et le pathologique (1943, 1966, trad. esp. 1971, México, Siglo XXI), aunque la idea constituye el núcleo de toda su obra. Recientemente se han publicado dos excelentes estudios sobre su obra: DAGOGNET, F. (1997), Georges Canguilhem, philosophe de la vie, Le Plessis-Robinson, Institut Synthélabo. DeBru, C. (2004), Georges Canguilhem, science et non-science, Paris, Editions Rue d'Ulm.

19 Para comprobarlo basta con echar un vistazo a algunas de las páginas de una obra extraordinaria: LAIN ENTRALGO, P. (1950), La historia clínica. Historia y teoría del relato patográfico, Madrid, CSIC. Reeditada en 1998, Madrid, Triacastela, p. ej. 95, 99, 115, 134. 
forma de hacer medicina en algunas de las más importantes universidades de Alemania. Este dato es suficientemente provocativo como para querer saber más acerca de la vida del personaje. En efecto: ¿cómo llega alguien que «no ha pasado a la historia» - al menos no en medida comparable a otros innovadores - a hacer entrar en la universidad una materia absolutamente sospechosa, contando, además — como suele señalarse en los citados estudios- con la oposición frontal de los claustros de dichas facultades y con la del Ministerio de Cultura prusiano? Si a esto añadimos que este personaje vuelve a aparecer, casi treinta años más tarde, en la crónica de sucesos parisina a causa de un proceso judicial del que se hacen eco la prensa y no pocos escritores franceses de la época, y que este proceso tiene por objeto un tratamiento magnético realizado sobre una dama perteneciente a la nobleza inglesa, resulta difícil concebir una historia del magnetismo animal basada solamente en la lectura de los textos doctrinales a éste tema dedicados. Afortunadamente existen biografías de Koreff, cuatro al menos que yo $\operatorname{conozca}^{20}$. La mejor de ellas, la de Oppeln-Bronikowski, ostenta un significativo subtítulo: «la novela de la vida de un olvidado». Ciertamente la vida del olvidado Koreff (un olvidado era cuando el autor se ocupó de él, y a mi parecer sigue siéndolo) parece una novela. Pero no es menos cierto lo que también - a continuación - reza dicho subtítulo: «compuesta a partir de documentos». Nada hay en ella que sea fantaseado, hasta el punto de que, en ocasiones, llega a resultar árida. Sencillamente es novelesca porque así lo quisieron las circunstancias.

\section{BIOGRAFÍAS MÉDICAS... ¿HISTORIA VIVA DE LA MEDICINA?}

En la perspectiva que he adoptado podría, pues, esbozarse una respuesta a la pregunta con la que comenzaba mi reflexión: qué queremos decir cuando decimos —o algo nos hace decir— «biografías médicas». Sin quitarle un ápice de

20 Varnhagen Von Ense, K. A. [1871] (1971), " Koreff », en Biographische Portraits, Bern, Herbert Lang, pp.1-58. MARTIN, M. [1925] (1977), Le docteur Koreff (1783-1851), Genève, Slatkine Reprints. OpPELn-BronikowsKi,F. v. (1928), David Ferdinand Koreff. Serapionsbruder, Magnetiseur, Geheimrat und Dichter. Der Lebensroman eines Vergessenen. Aus Urkunden zusammengestellt und eingeleitet von..., Berlin-Leipzig, Paetel. No he conseguido aún la cuarta, de la que solo poseo una referencia incompleta a través de ARTELT, W. (1965). «Der Mesmerismus in Berlin». Akademie der Wissenschaften und der Literatur, Abhandlungen der Geistes- und Sozialwissenschaftlicher Klasse, 6, 391-474 (p. 392). Su autor es Kurt Groba y está publicada en el tercer volumen de Schlesische Lebensbilder, también en 1928. A juicio de Artelt no supera a la de Oppeln-Bronikowski. 
mérito, el célebre Sigerist escribió sobre «grandes médicos» ${ }^{21}$. Más certero en la elección de título, Laín acometió el estudio de «clásicos de la medicina» ${ }^{22}$. Otros historiadores, que no han sido, ni probablemente serán célebres, han estudiado, venciendo sin duda notables dificultades técnicas, las biografías de médicos menos grandes y nada clásicos, pero yo les debo al menos tanta gratitud como a los maestros: Walter Brednow, Otto Joachim Grüsser, Ekkehart Meffert, Friedrich von Oppeln-Bronikowski ${ }^{23}$, me han permitido comprender mejor un período de la historia de la medicina que en mis «años de aprendizaje» se presentaba como totalmente carente de interés; y eso, sencillamente por mostrar algo que, supuestamente es imprescindible, pero a veces se busca solamente en otra parte: el contexto. En la peripecia biográfica de médicos que no han producido revolución alguna en la medicina he encontrado a menudo cuanto a ese respecto podía desear: datos concretos, o cuando menos la mención de eventos que de otro modo me resultarían desconocidos y que, así, podía rastrear. Y con ellos, el sentido de muchas cosas que aparentemente carecían de él. Y también los testimonios biográficos de contemporáneos, como el citado de Varnhagen sobre Koreff, y autobiografías salpicadas de referencias a otros autores, como la de Steffens ${ }^{24}$ me han regalado valiosísimas informaciones sobre esa preocupación, para mí esencial, sobre el sentido: las que, como en negativo, suministra la imagen de una época idealizada sin querer - favorable o desfavorablemente - por quienes la han vivido.

A mi parecer, en las biografías revive, o se vivifica ante nosotros, una época. Los datos concretos que suministran deben sin duda ser contrastados con los procedentes de otras fuentes; pero tanto en la autobiografía como en la biografía escrita por un contemporáneo, y también en la compuesta desde la

21 Sigerist, H. (1931), Grosse Ärzte. Eine Geschichte der Heilkunde in Lebensbildern, München, 1931.

22 Me refiero a la colección editada por el Consejo Superior de Investigaciones Científicas que lleva ese nombre, compuesta por los volúmenes dedicados a Bichat (1946), Harvey (1948), Laennec (1954), y Sydenham (con Agustín Albarracín, 1961), a los que hay que añadir el Lombroso de J. L. y M. Peset (1975). Exceptúo el consagrado a la medicina hipocrática por razones obvias.

23 Los menciono de manera «autobiográfica», en el orden en que se produjo mi encuentro con ellos. Brednow, W. (1970), Dietrich Georg Kieser. Sein Leben und Werk, Wiesbaden, Franz Steiner. GRÜSSER, O. J. (1987), Justinus Kerner. Arzt, Poet, Geisterseher, Berlin, Springer. MEFFERT, E. (1999), Carl Gustav Carus. Arzt-Künstler-Goetheanist. Eine biographische Skizze, Basel, Perseus. La obra de Oppeln-Bronikowski sobre Koreff ya ha sido citada.

24 Steffens, H. [1840-1844] (1995), Was ich erlebte, Stuttgart-Bad Cannstatt, Frommann-Holzboog. 
distancia, pero con rigor y sensibilidad, está presente algo que, a mi parecer, no tiene precio: la atmósfera; aquello que decide si el historiador va a llegar a participar en su historia, o si va a limitarse a considerarla.

Presiento que las líneas precedentes harán aparecer, como por ensalmo, la correspondiente pareja de «tipos psicológicos» — con la venia de C.G. Jungen el territorio de los historiadores, pues no se me oculta que muchos preferirán, sin duda apoyándose en sólidos argumentos, una historia distanciada de su objeto. Esto no me inquieta. Probablemente la única manera de aproximarse a nuestro escurridizo objetivo común sea poner en juego ambas estrategias e intercambiar los resultados, como en el presente intercambian sus camisetas los jugadores de dos equipos de fútbol que acaban de enfrentarse, o como en tiempos pasados acostumbraban hacer con sus regalos los señores de territorios fronterizos de similar poderío, convirtiendo la diferencia en cultura. Porque no hay una sola forma válida de hacer historia de la medicina (el señor que habla desde este territorio sólo se alzaría en armas contra quien tal pretendiera) y la belleza de lo verdadero se despliega en esa multiplicidad. 